\title{
Sistem Pengambilan Keputusan untuk Penerimaan Pegawai Baru PT.PLN (Persero) Wilayah Aceh dengan Metode Heuristik
}

\author{
Ira Zulfa ${ }^{1}$, I Nyoman Tri Anindia Putra ${ }^{2}$ \\ 1Teknik Informatika, Sekolah Tinggi Teknik PLN \\ Jakarta, Indonesia \\ 1ira.zulfaa@gmail.com \\ 2Teknik Informatika,STMIK STIKOM INDONESIA \\ Denpasar, Indonesia \\ , 2trianindiaputra@gmail.com2
}

\begin{abstract}
Abstrak
Decision Support Systems atau yang sering disingkat DSS juga merupakan Sistem pendukung keputusan merupakan metode yang dipakai untuk mendukung pengambilan keputusan dalam suatu organisasi atau perusahaan pada bidang sistem informasi berbasis komputer (manajemen pengetahuan).

Heuristik merupakan pengembangan dari berbagai aturan yang membantu memecahkan masalah rumit atau sud dari masalah final yaitu menemukan jalur yang paling meyakinkan dalam menemukan solusi dan cara mendapatkan solusi dengan menginterpretasi informasi yang senantiasa berubah lalu mengembangkan metode yang memimpin kepada satu algoritma komputasional atau solusi umum.

Metode ini dipilih karena akan melakukan pencarian terhadap solusi yang cukup baik melalui serangkaian aturan (rules) yang akan dibentuk dengan format IF anteseden THEN. Konsekuen anteseden berisi aksi atau kondisi atau fakta yang terjadi konsekuen berupa reaksi yang dilakukan, jika aksi terjadi atau kondisi bernilai benar, adalah untuk menentukan pelamar mana yang pantas dipilih yang akan mengikuti tahapan tes berikutnya, berdasarkan persyaratan-persyaratan yang telah ditentukan sehingga akan mendapatkan hasil yang lebih akurat terhadap siapa saja pelamar yang berhak mengikuti tahap tes berikutnya untuk menjadi pegawai baru PLN.
\end{abstract}

Kata Kunci: Sistem Pendukung Keputusan, Metode Heuristik, Penerimaan Pegawai baru, Sistem Informasi

\section{Pendahuluan}

Informasi yang akurat serta tepat waktu dalam menyajikan data yang lengkap sangat dibutuhkan oleh instansi, organisasi dan perusahaan. Komputer yang fungsinya sebagai tools dalam mengelola data menjadi informasi yang benar, akurat, tepat guna dan tepat waktu [1].

Sebagai bagian dari PT.PLN (Persero) Wilayah ACEH. Human Resource Departement (HRD) adalah bagian yang memiliki peranan cukup penting di perusahaan. Human Resource Departement (HRD) diharuskan untuk memiliki sistem informasi yang baik. Berdasarkan pertimbangan pentingnya hal diatas, sehingga dukungan sistem informasi cepat dan akurat sangat diperlukan, sistem informasi juga wajib bisa berbasis jaringan dengan arsitektur client server.

Hal ini karena pada proses pengolahan data pegawai baru melibatkan beberapa bagian dari perusahaan, sehingga sistem informasi harus bisa menangani masalah sharing data dan access data online dengan cepat, baik dan relevan. Tetapi sistem yang berjalan sekarang ini bahwa sistem belum terkomputerisasi.

Dalam mengatasi masalah di atas, maka PT.PLN (Persero) Wilayah ACEH mengusulkan untuk merancang sistem pengambilan keputusan mengenai penerimaan pegawai baru mengggunakan metode hueristik yang akan membantu sistem dalam pengambilan keputusan 
untuk penyaringan calon pegawai baru PT. PLN (persero) wilayah ACEH pertahap demi tahap. Dan diharapkan sistem informasi ini dapat dijadikan salah satu solusi, kebutuhan akan sistem informasi tepat, cepat dan akurat bisa menangani masalah akan informasi dan data pegawai baru secara khusus, bagi Human Resource Departement (HRD) maupun bagian perusahaan lainnya dan masalah sharing data dan access data online dengan cepat, baik dan relevan. Dengan dirancangnya aplikasi ini diharapkan dapat membantu calon pegawai baru khususnya bagian Human Resource Departement (HRD), Agar dapat menyeleksi dan menyediakan sumber daya manusia yang berpotensial dan berkualitas. Sistem informasi menggunakan metode heuristik yang membantu mengambil keputusan dalam penyaringan calon pegawai sehingga dapat membuat kebijakan yang lebih cepat untuk dihasilkan.

Berdasarkan latar belakang di atas, penulis bermaksud merancang suatu sistem informasi yang dapat membantu bagian Human Resource Departement (HRD), seperti dapat mengupdate informasi terbaru tentang pengrecriutan, mengambil keputusan dengan penyeleksian menggunakan metode Heuristik sebagai tema dari penulisan Tugas Akhir yang berjudul "SISTEM PENGAMBILAN KEPUTUSAN UNTUK PENERIMAAN PEGAWAI BARU PT. PLN (PERSERO) WILAYAH ACEH DENGAN METODE HEURISTIK"

\section{Metode Penelitian}

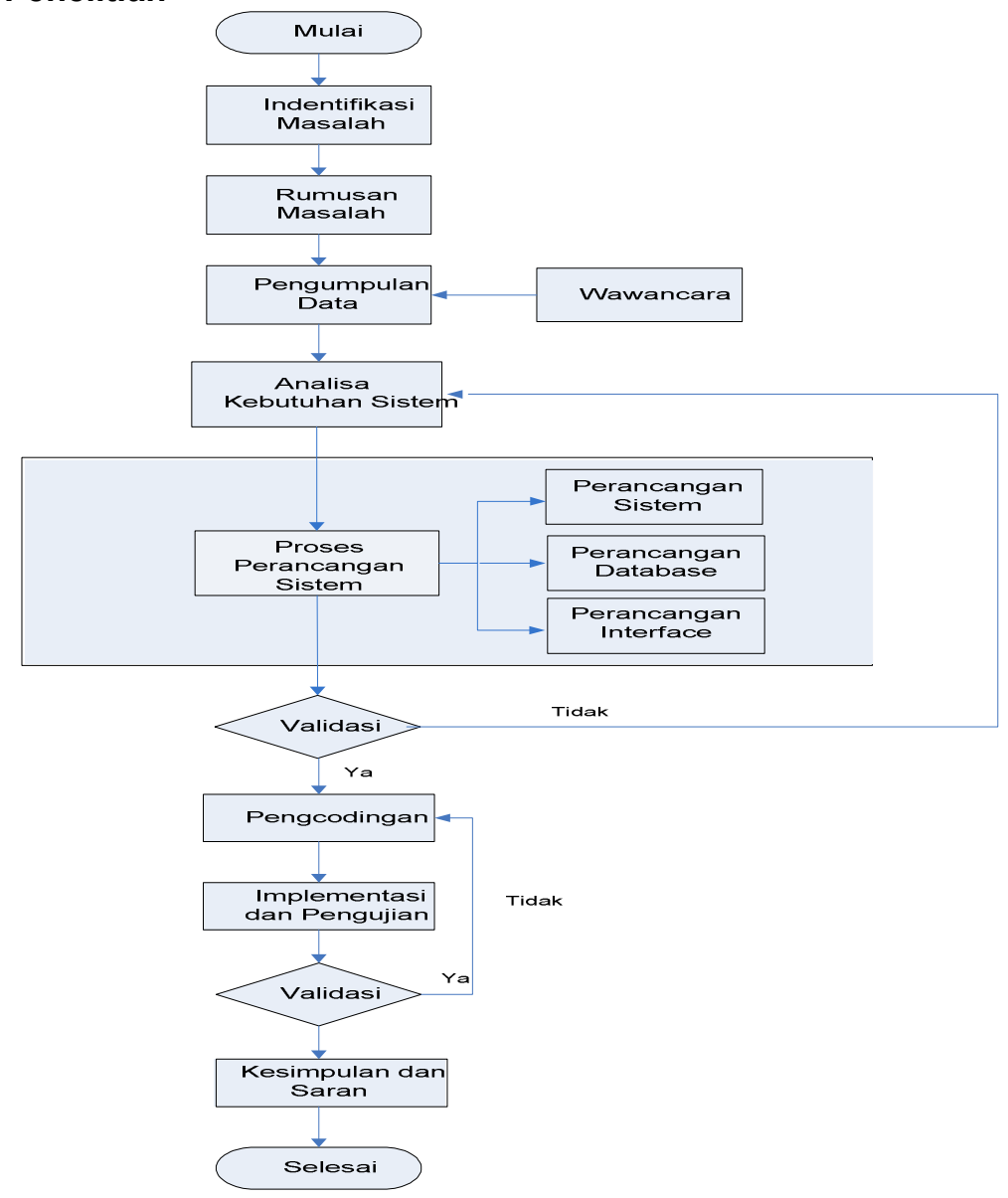

Gambar 1. Diagram Alir Penelitian

Penelitian dilakukan sebagaimana Gambar 1 diatas, yang mana pengumpulan data adalah mengumpulkan bahan-bahan yang diperlukan, penulis menggunakan metode wawancara Kepada wakil kepala HRD dan pegawai PT. PLN (persero) wilayah ACEH Menggunakan data-data yang telah ada sebelumnya, agar penulis memiliki pengetahuan dasar yang kuat dan memadai. 
Analisa yang dilakukan yaitu terhadap sistem database,kebutuhan fungsional dan non fungsional sistem yang akan dirancang. Analisa hardware dan software yang digunakan dan pengguna yang akan menggunakan sistem [2].

Perancangan akan di implementasikan dengan menggunakan PHP sebagai bahasa pemrograman berbasis web, dan basis data di implementasikan dengan MySQL [3].

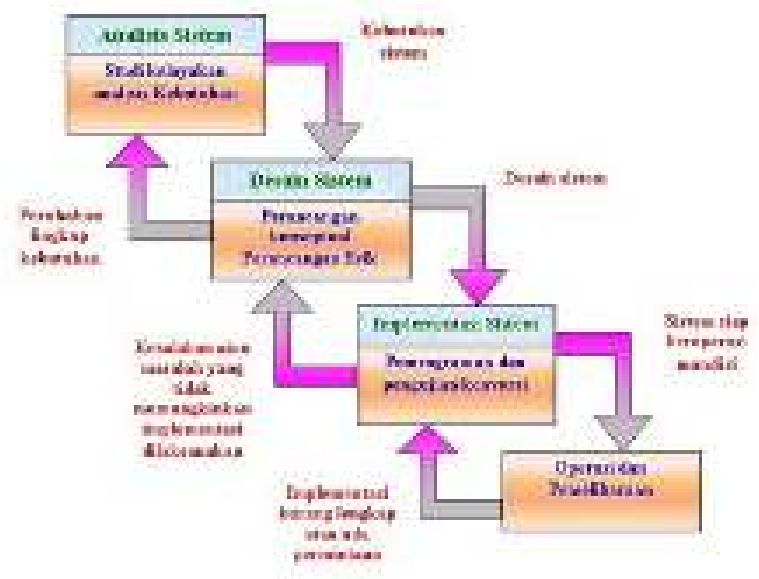

Gambar 2. Waterfall Perancangan Sistem Informasi

Fase-fase dalam model waterfall meliputi:

a. Analisis kebutuhan dan pendefinisiannya (Requirements).

Fase ini merupakan fase awal yaitu menumpulkan kebutuhan yang harus dipenuhi oleh perangkat lunak yang akan dibangun.

b. Perancangan sistem dan perangkat lunak (System and Software Design).

Pada fase ini menerjemahkan kebutuhan ke dalam desain yang mempresentasikan perangkat lunak uang dapat diukur kualitasnya sebelum memulai pada fase coding [4].

c. Implementasi dan unit testing (Implementation and unit testing).

Fase ini merupakan menerjemahkan desain perangkat lunak ke dalam kode-kode program.

d. Integrasi dan pengujian sistem (Integration and system testing).

(Fase ini dilakukan dengan menyatukan unit-unit perangkat lunak kemudian diuji secara keseluruhan [5].

e. Pengoperasian

Fase ini merupakan fase terakhir dimana aplikasi yang telah dibangun dioperasikan dalam lingkungannya.

\subsection{Analisa Kebutuhan Sistem}

\subsubsection{Kebutuhan Input}

Data para pelamar yang Akan mendaftar sebagai peagawai baru, data pelamar yang diperoleh, dihimpun dalam sebuah table, melakukan penyaringan data yang terbaik untuk setiap persyaratan, dan mengantarkan informasi tersebut ke pihak yang bersangkutan.

\subsubsection{Kebutuhan Proses}

Pembuatan Aplikasi Penerimaan Pegawai Baru dengan Metode Heuristik, Dengan Metode ini, diharapkan penyeleksian akan lebih tepat, karena didasarkan pada rule-rule yang telah dibuat dan masing-masing nilai dari rules yang sudah ditentukan, sehingga akan mendapatkan hasil yang lebih akurat terhadap siapa saja pelamar yang berhak mengikuti tahap tes berikutnya untuk menjadi pegawai baru PLN. 


\subsubsection{Kebutuhan Output}

Output yang diharapkan dari sistem informasi ini adalah Pelamar bisa melihat langsung pengumuman hasil dari penyeleksian tersebut via online. Berisi bagaimana data dikumpulkan, sumber data dan cara analisis data.

\subsection{Perancang Sistem}

Untuk kemudahan dalam perancangan sistem informasi ini, maka penulis menjabarkan Hirarki Menu Pilihan sebagai berikut :

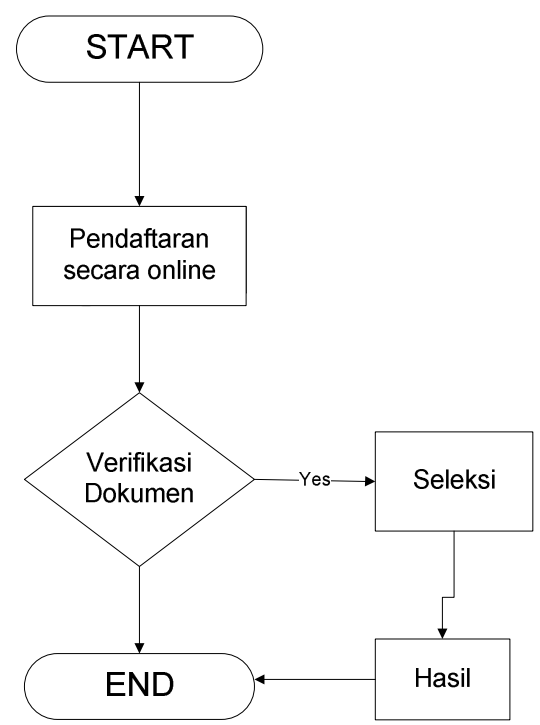

Gambar 3. Flowchart proses pendaftaran pegawai baru

Berdasarkan Gambar di atas, untuk memulai pelamar harus mendaftar secara online, setelah mengisi formulir pendaftaran secara online maka akan dilakukan verifikasi data, jika data yang ada lengkap dan memenuhi persyaratan yang diminta maka akan di seleksi, tetapi jika data yang ada tidak lengkap dan tidak memenuhi persyaratan yang diminta maka gugur.

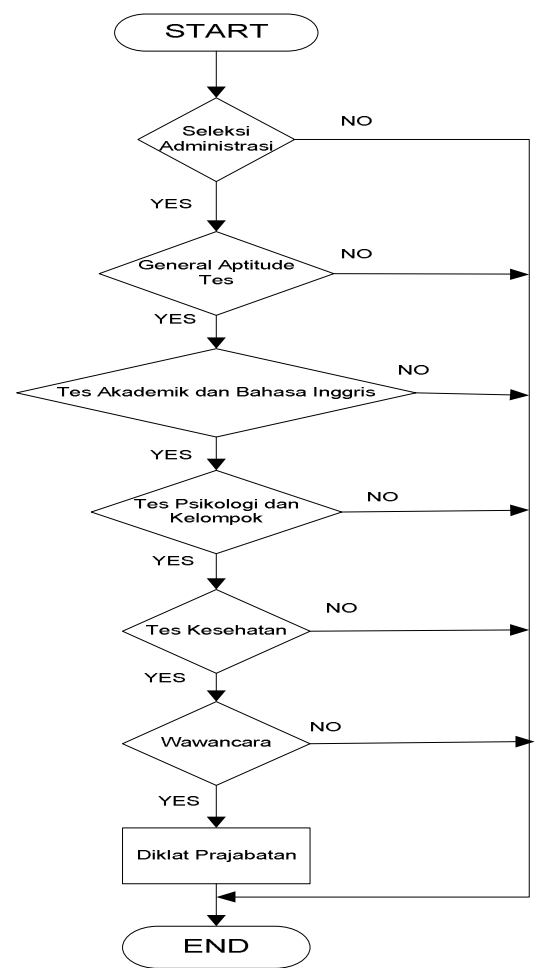

Gambar 4. Flowchart tahap seleksi penerimaan pegawai baru 
Berdasarkan gambar di atas, untuk melanjutkan ke tahap seleksi berikutnya pelamar harus lolos tahap seleksi administrasi, tetapi jika tidak maka akan gugur, dan jika iya maka akan lanjut ke tes general aptitude, jika lolos lagi maka akan lanjut ke tes akademik dan bahasa inggris, jika lolos lagi maka akan lanjut ke tes psikologi dan kelompok, jika lolos lagi maka akan lanjut lagi ke tes kesehatan yang merupakan tes terakhir, selanjutnya jika lolos tes terakhir maka akan diwawancara dan bila di terima akan menjadi pegawai PLN.

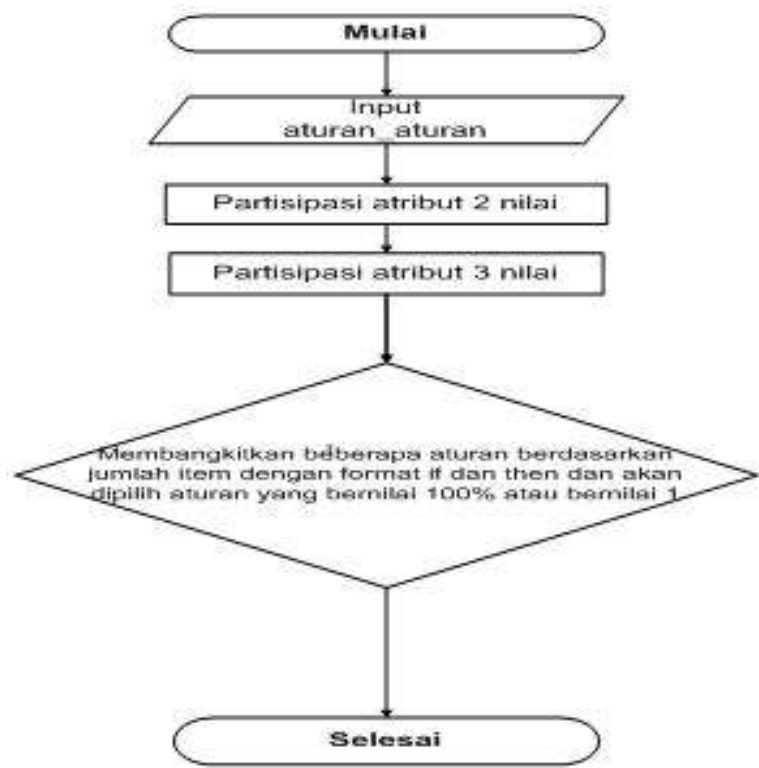

Gambar 5. Flowchart metode heuristik

Berdasarkan Gambar di atas, untuk menggunakan metode heuristik, maka pertama akan ditetapkannya aturan-aturan dari masalah yang ada, selanjutnya membangun atribut 2 nilai dengan aturan yang mengandung kedua nilai tersebut dengan banyak kejadian $>1$, dan juga membangun atribut 3 nilai dengan aturan yang

\section{Hasil dan Pembahasan}

Pada Hasil dan Pembahasan ini, penulis akan membahas mengenai penerapan metode heuristik pada sistem informasi penerimaan pegawai baru.

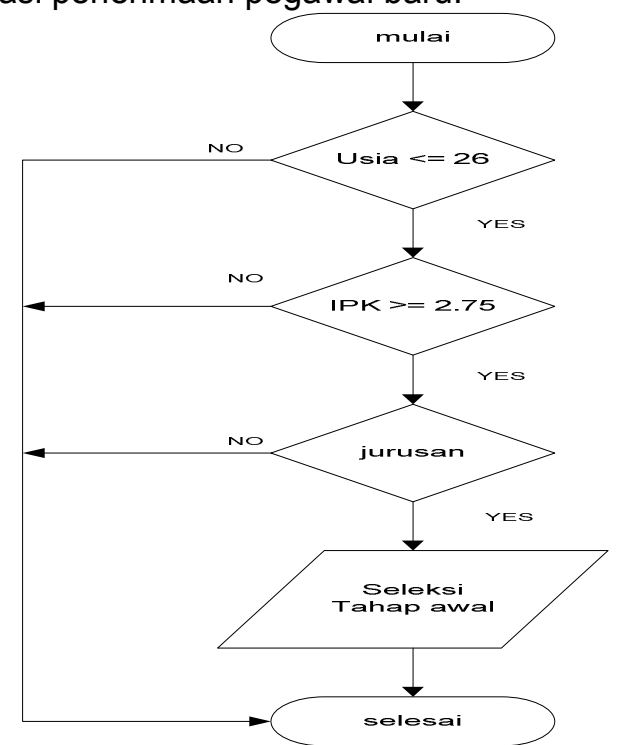

Gambar 6.Flowchart seleksi pegawai baru dengan metode heuristic 
Berrdasarkan gambar di atas, untuk mendaftar pelamar harus memenuhi kriteria atau persyaratan yang di minta oleh PT.PLN (persero) wilayah ACEH, kriteria tersebut sebagaimana flowchart di atas, pertama, jika usia pelamar $<=26$, ipk $>=2,75$, jurusan yg dibutuhkan sesuai dengan posisi jabatan yang dituju,dan jika semua persyaratan terpenuhi maka selanjutnya akan di seleksi menggunakan metode heuristic dengan mencari data terbaik untuk lolos mengikuti tahap seleksi berikutnya, dan jika tidak memenuhi salah satu persyaratan yang diminta maka pelamar akan di anggap gugur.

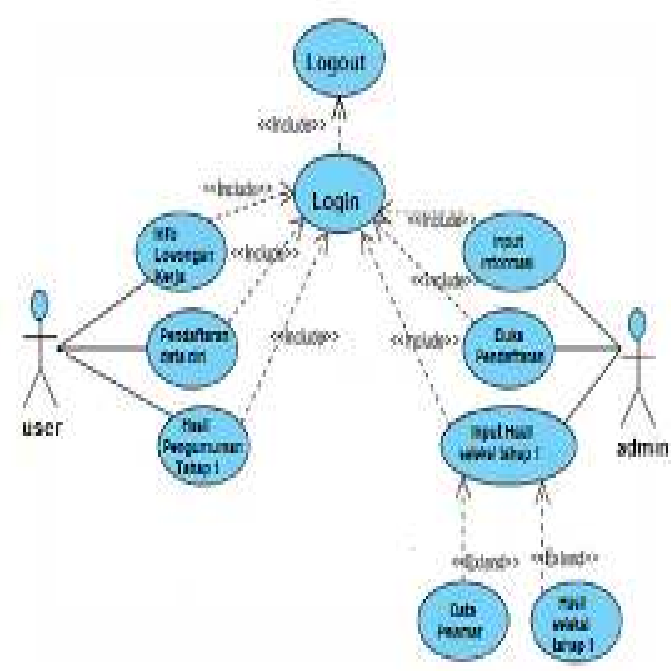

Gambar 7.Use case diagram penerimaan pegawai baru

Berdasarkan Gambar 7, Untuk bisa masuk ke sistem informasi ini user dan admin harus login dahulu degan measukan id dan password masing-masing, dan setelah login berhasil bagi user dapat melihat info lowongan kerja, juga dapat mendaftar dengan mengisi form data diri, dan hasil seleksi tahap pertama, sedangkan bagi admin dapat menginput informasi, hasil seleksi tahap pertama, dan membuka pendaftaran bagi user.

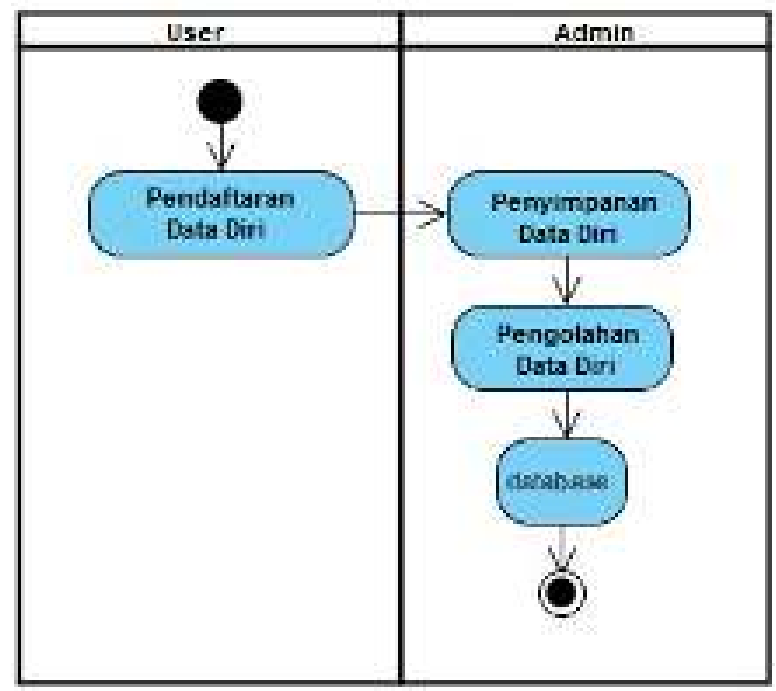

Gambar 8. Collaboration Diagram pada penyeleksian tahap awal penerimaan pegawai baru

Berdasarkan Gambar 8, user mendaftarkan data diri, dan data diri yang telah diisi oleh user akan disimpan oleh admin, selanjutnya akan diolah, dan tersimpan menjadi database. 


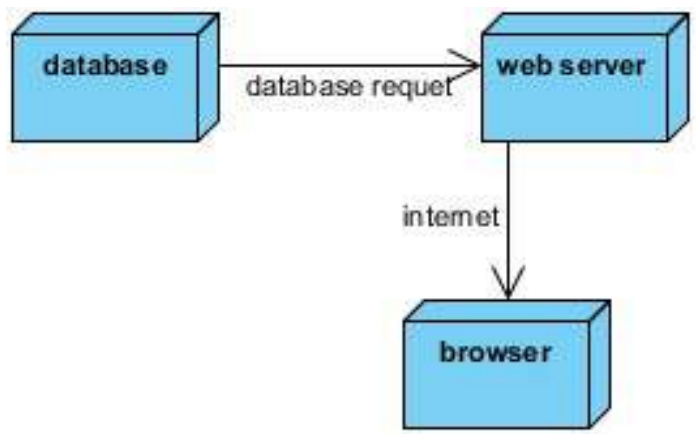

Gambar 9. Deployment Diagram penyeleksian tahap awal

Berdasarkan gambar di atas, komponen akan terletak (pada mesin, server atau piranti keras), dengan kemampuan jaringan pada lokasi tersebut, spesifikasi server, dan hal-hal lain yang bersifat Deployment atau physical.

\begin{tabular}{|c|c|c|c|c|}
\hline $\begin{array}{l}\text { Atura } \\
\text { n } \\
\mathrm{Ke}-\end{array}$ & $\begin{array}{l}\text { Strat } \\
\text { a } \\
\text { (C1) }\end{array}$ & $\begin{array}{l}\text { Um } \\
\text { ur } \\
\text { (C2) }\end{array}$ & $\begin{array}{l}\text { IPK } \\
\text { (C3 } \\
\text { ) }\end{array}$ & Jurusan (C4) \\
\hline 1 & S1 & 22 & 2,7 & Teknik mesin \\
\hline 2 & S1 & 22 & 3,0 & Teknik mesin \\
\hline 3 & S1 & 22 & 3,2 & $\begin{array}{l}\text { Teknik } \\
\text { informat } \\
\text { ika }\end{array}$ \\
\hline 4 & S1 & 23 & 3,3 & $\begin{array}{l}\text { Teknik } \\
\text { informat } \\
\text { ika }\end{array}$ \\
\hline 5 & S1 & 23 & 3,3 & Teknik elektro \\
\hline 6 & S1 & 23 & 3,2 & Teknik elektro \\
\hline 7 & S1 & 24 & 3.0 & Teknik elektro \\
\hline 8 & S1 & 24 & 2,9 & $\begin{array}{l}\text { Teknik } \\
\text { informat } \\
\text { ika }\end{array}$ \\
\hline 9 & S1 & 22 & 3,0 & $\begin{array}{l}\text { Teknik } \\
\text { informat } \\
\text { ika }\end{array}$ \\
\hline 10 & S1 & 23 & 2,9 & Teknik elektro \\
\hline
\end{tabular}


Untuk proses penyaringan tahap awal, telah dihimpun 10 aturan. Ada 4 atribut yang digunakan, yaitu:

1. Strata atau jenjang pendidikan yang diminta (C1),

2. Umur atau usia yang diminta (C2),

3. IPK (indeks prestasi kumulatif) yang diminta (C3), dan

4. Jurusan atau bidang studi yang diminta (C4).

Pertama, menunjukkan partisipasi atribut (kejadian) dengan satu nilai, misal C1 $=$ S1 Nilai (10)

○ Satu item

\begin{tabular}{|l|l|}
\hline No & 1 item \\
\hline 1 & $\mathrm{C} 1=\mathrm{S} 1(10)$ \\
\hline
\end{tabular}

Kedua, menunjukkan partisipasi atribut (kejadian) dengan 2 nilai.

Misal $\mathrm{C} 1=\mathrm{S} 1$ dan $\mathrm{C} 2=22$, ada 4 aturan yang mengandung kedua nilai tersebut (dengan banyak kejadian $>1$ ).

O Dua item

\begin{tabular}{|l|l|}
\hline No & 2 item \\
\hline 1 & $\begin{array}{l}\text { C1 }=\text { S1 } \\
\text { C2 }=22(4)\end{array}$ \\
\hline 2 & $\begin{array}{l}\text { C1 }=\text { S1 } \\
\text { C3 }=23(4)\end{array}$ \\
\hline 3 & $\begin{array}{l}\text { C1 }=\text { S1 } \\
\text { C3 }=24(2)\end{array}$ \\
\hline
\end{tabular}

Ketiga, menunjukkan partisipasi atribut (kejadian) dengan 3 nilai.

Misal $\mathrm{C} 1=\mathrm{S} 1, \mathrm{C} 2=22 \mathrm{dan} \mathrm{C} 4=3,00$ ada 2 aturan yang mengandung kedua nilai tersebut (dengan banyak kejadian $>1$ ).

- Tiga item

\begin{tabular}{|l|l|}
\hline No & 3 item \\
\hline 1 & $\begin{array}{l}\text { C1 }=\text { S1 } \\
\text { C2 }=22 \\
\text { C3 }=3,00(2)\end{array}$ \\
\hline 2 & $\begin{array}{l}\text { C1 }=\text { S1 } \\
\text { C2 }=23 \\
\text { C3 }=3,35(2)\end{array}$ \\
\hline 3 & $\begin{array}{l}\text { C1 }=\text { S1 } \\
\text { C2 }=22 \\
\end{array}$ \\
C4 $=\mathrm{TM}(2)$ \\
\hline 4 & C1 $=$ S1 \\
& C2 $=22$ \\
& C4 $=\mathrm{TI}(3)$ \\
\hline 5 & C1 $=$ S1 \\
& C2 $=23$ \\
& C4 $=$ TE (3) \\
\hline
\end{tabular}


Dari data tersebut, dapat dibangkitkan beberapa aturan berdasarkan jumlah item yang tersedia. Misalkan untuk 1 item, $\mathrm{C} 1=\mathrm{S} 1$, dapat dibentuk 1 aturan:

1. If - then $\mathrm{C} 1=\mathrm{S} 1$

Untuk 2 item, $\mathrm{C} 1=\mathrm{S} 1$ dan $\mathrm{C} 2=22$, dapat dibentuk 3 aturan:

2. If $\mathrm{C} 1=\mathrm{S} 1$ then $\mathrm{C} 2=22 \quad(4 / 10)$

3. If $\mathrm{C} 2=22$ then $\mathrm{C} 1=\mathrm{S} 1 \quad(4 / 4)$

4. If - then $\mathrm{C} 1=\mathrm{S} 1$ and $\mathrm{C} 2=22$

5. If $\mathrm{C} 1=\mathrm{S} 1$ then $\mathrm{C} 2=23 \quad(4 / 10)$

6. If $\mathrm{C} 2=23$ then $\mathrm{C} 1=\mathrm{S} 1 \quad(4 / 4)$

7. If - then $\mathrm{C} 1=\mathrm{S} 1$ and $\mathrm{C} 2=23$

8. If $\mathrm{C} 1=\mathrm{S} 1$ then $\mathrm{C} 2=24 \quad(2 / 10)$

9. If $\mathrm{C} 2=24$ then $\mathrm{C} 1=\mathrm{S} 1 \quad(2 / 2)$

10. If - then $\mathrm{C} 1=\mathrm{S} 1$ and $\mathrm{C} 2=24$

11. If $\mathrm{C} 1=\mathrm{S} 1$ then $\mathrm{C} 2=24 \quad(2 / 10)$

12. If $\mathrm{C} 2=24$ then $\mathrm{C} 1=\mathrm{S} 1 \quad(2 / 2)$

13. If - then $\mathrm{C} 1=\mathrm{S} 1$ and $\mathrm{C} 2=24$

Untuk 3 item, $\mathrm{C} 1=\mathrm{S} 1, \mathrm{C} 2=22$, dan $\mathrm{C} 3=3,00$ dapat dibentuk 3 aturan:

14. If $\mathrm{C} 2=22$ then $\mathrm{C} 1=\mathrm{S} 1$ and $\mathrm{C} 3=3,00 \quad 2 / 4$

15. If $\mathrm{C} 3=3,00$ then $\mathrm{C} 1=\mathrm{S} 1$ and $\mathrm{C} 2=22 \quad 2 / 3$

16. If - then $\mathrm{C} 1=\mathrm{S} 1$ and $\mathrm{C} 2=22$ and $\mathrm{C} 3=3,00$

17. If $\mathrm{C} 2=22$ then $\mathrm{C} 1=\mathrm{S} 1$ and $\mathrm{C} 4=\mathrm{TM} \quad 2 / 4$

18. If $\mathrm{C} 4=\mathrm{TM}$ then $\mathrm{C} 1=\mathrm{S} 1$ and $\mathrm{C} 2=222 / 2$

19. If - then $\mathrm{C} 1=\mathrm{S} 1$ and $\mathrm{C} 2=22$ and $\mathrm{C} 4=\mathrm{TM} 2 / 10$

20. If $\mathrm{C} 2=22$ then $\mathrm{C} 1=\mathrm{S} 1$ and $\mathrm{C} 4=\mathrm{TI} 3 / 4$

21. If $\mathrm{C} 4=\mathrm{TI}$ then $\mathrm{C} 1=\mathrm{S} 1$ and $\mathrm{C} 2=22 \quad 3 / 4$

22. If - then $\mathrm{C} 1=\mathrm{S} 1$ and $\mathrm{C} 2=22$ and $\mathrm{C} 4=\mathrm{TI}$

23. If $\mathrm{C} 2=23$ then $\mathrm{C} 1=\mathrm{S} 1$ and $\mathrm{C} 4=\mathrm{TE}$

24. If $\mathrm{C} 4=\mathrm{TE}$ then $\mathrm{C} 1=\mathrm{S} 1$ and $\mathrm{C} 2=233 / 4$

25. If - then $\mathrm{C} 1=\mathrm{S} 1$ and $\mathrm{C} 2=23$ and $\mathrm{C} 4=\mathrm{TE}$

$2 / 10$

Demikian seterusnya, total terdapat 25 aturan yang dapat dibentuk seperti:

Selanjutnya, dapat ditentukan tingkat akurasi yang kita harapkan untuk suatu aturan. Misalkan ditetapkan tingkat akurasi $=100 \%(1)$, hal ini berarti bahwa nilai proposisi suatu aturan harus bernilai 1 . 


\begin{tabular}{|c|c|c|c|c|}
\hline No & Aturan & $\begin{array}{l}\text { Cove- } \\
\text { rage }\end{array}$ & $\begin{array}{c}\text { Akura } \\
\mathrm{i} \\
\mathrm{i}\end{array}$ & $\begin{array}{l}\text { Asal } \\
\text { atura } \\
n\end{array}$ \\
\hline 1 & $\begin{array}{c}\text { If }- \text { then } \mathrm{C} 1 \\
=\mathrm{S} 1\end{array}$ & 10 & $100 \%$ & 1 \\
\hline 2 & $\begin{aligned} \text { If } C 2 & =22 \\
\text { then } C 1 & =S 1 \\
& (4 / 4\end{aligned}$ & 4 & $100 \%$ & 3 \\
\hline 3 & $\begin{array}{l}\text { If } \mathrm{C} 2=23 \\
\text { then } \mathrm{C} 1=\mathrm{S} 1 \\
(4 / 4 \\
)\end{array}$ & 4 & $100 \%$ & 6 \\
\hline 4 & $\begin{array}{l}\text { If } \mathrm{C} 2=24 \\
\text { then } \mathrm{C} 1=\mathrm{S} 1 \\
(2 / 2 \\
)\end{array}$ & 2 & $100 \%$ & 9 \\
\hline 5 & $\begin{array}{l}\text { If } \mathrm{C} 2=24 \\
\text { then } \mathrm{C} 1=\mathrm{S} 1 \\
(2 / 2 \\
\text { ) }\end{array}$ & 2 & $100 \%$ & 12 \\
\hline 6 & $\begin{array}{l}\text { If } \mathrm{C} 4=\mathrm{TM} \\
\text { then } \mathrm{C} 1=\mathrm{S} 1 \\
\text { and } \mathrm{C} 2=22\end{array}$ & 2 & $100 \%$ & 18 \\
\hline
\end{tabular}




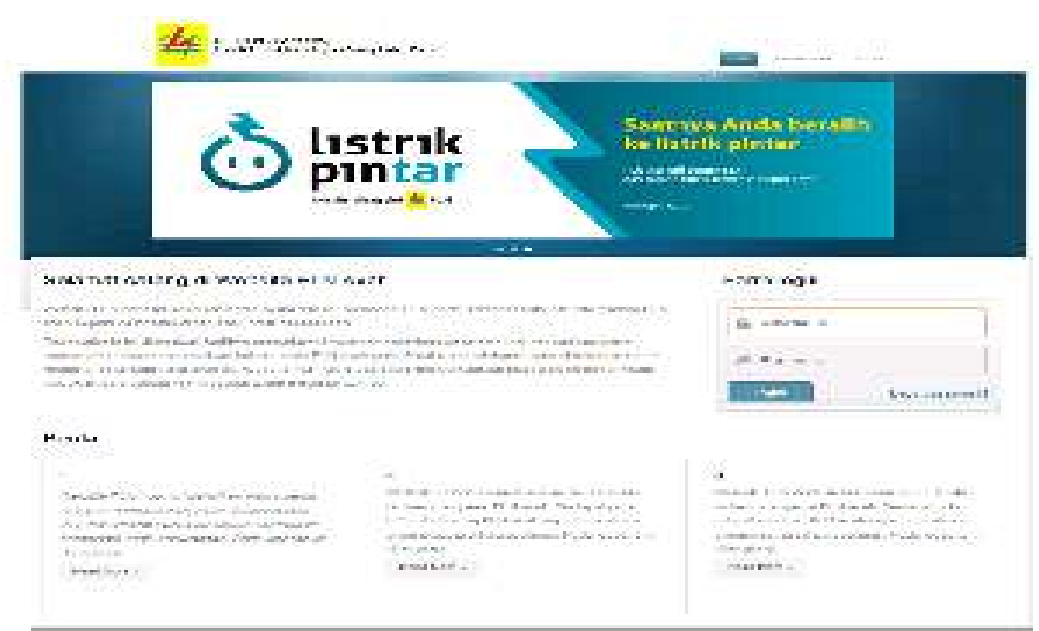

Gambar 9. Tampilan Form home sistem informasi penerimaan pegawai baru PLN.

Berdasarkan Gambar 9, Form ini merupakan tampilan awal dari aplikasi sistem informasi yang akan di access oleh user.

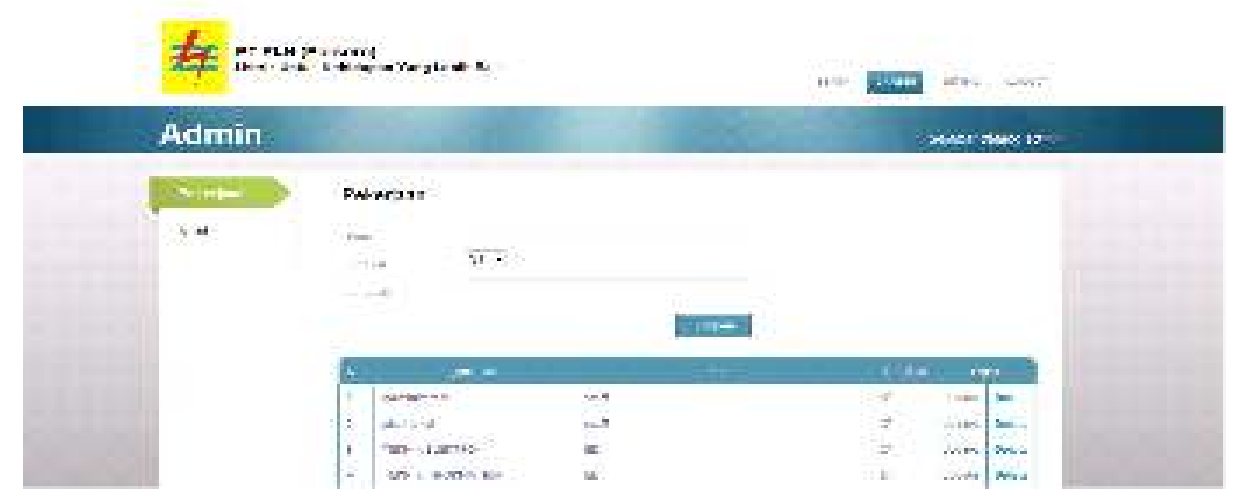

Gambar 10. Tampilan Form admin sistem informasi penerimaan pegawai baru PLN.

Berdasarkan Gambar 10, fungsi dari pada form ini untuk menginput pekerjaan, dimana mencakup posisi, tingkat, jurusan yang dapat diisi langsung oleh admin.

\section{SIMPULAN}

a. Sistem keamanan dalam aplikasi ini belum terjamin, untuk selanjutnya dapat dikembangkan menjadi aplikasi yang lebih terjamin keamanannya.

b. Sistem ini belum bisa menjelaskan secara sepenuh nya pengelolaan hasil tes calon pegawai baru secara lengkap atau jelas.

c. Meningkatkan desain tampilan Sistem Informasi penerimaan pegawai baru agar lebih menarik.

\section{DAFTAR PUSTAKA}

[1] Eniyati, S. \& Santi, R.C.N., 2010. Perancangan Sistem Pendukung Keputusan Penilaian Prestasi Dosen Berdasarkan Penelitian dan Pengabdian Masyarakat. Jurnal Teknologi Informasi DINAMIK, 15(2), pp.136-142.

[2] Madcoms. (2004). Aplikasi program PHP dan MY SQL untuk membuat website interaktif. Madiun: Madcoms

[3] Raharjo, Budi dkk. (2010). Modul Pemograman WEB (HTML,PHP,\& MY SQL). Bandung: Modula.

[4] Marinda. Linda. (2004). Sistem Basis Data. Yogyakarta: Andi.

[5] Puspitosari, Heni. (2011). Pemograman Web Database dengan PHP dan MY SQL, Tingkat Lanjut. Yogyakarta: Skripta. 
Jurnal IImu Komputer VOL. XI No. 2

p-ISSN: 1979-5661

e-ISSN: 2622-321X 